\title{
Corrosão de refratários utilizados na siderurgia. Parte II: Propriedades físicas dos refratários e fatores operacionais
}

\section{(Corrosion of refractories used in steel metallurgy. Part II: Refractories physical properties and operating factors)}

\author{
S.R. Bragança \\ Universidade Federal do Rio Grande Sul - DEMAT/UFRGS, Av. Osvaldo Aranha 99/705, \\ Porto Alegre, RS 90035-190 \\ saulorb@ufrgs.br
}

\begin{abstract}
Resumo
Foi realizada uma revisão dos principais aspectos encontrados na literatura especializada sobre corrosão de refratários, avaliando-se a viabilidade de determinados ensaios e relacionando-os com os resultados experimentais. Na primeira parte deste trabalho foram abordadas as principais propriedades da microestrutura dos refratários, como a qualidade dos agregados e da matriz, incluindo-se a fase ligante (como resinas ou piche), presença de carbono, porosidade e aditivos antioxidantes. Nesta segunda parte os demais aspectos ligados à corrosão, como as propriedades físico-químicas dos refratários, as características das escórias e das condições operacionais são discutidas, sempre, relacionando-se a teoria com dados da prática industrial. Especificamente, analisaram-se os refratários de linha de escória de panela de aço. Palavras-chave: refratários, corrosão, aciaria, escórias.
\end{abstract}

\section{Abstract}

In this study, the main aspects found in the literature about refractories corrosion were reviewed, evaluating the feasibility of certain tests and relating them with experimental results. In the first part of this work, the main properties of the microstructure of the refractories were discussed, such as aggregates and the matrix, including the binder phase (resins or pitch), presence of carbon, porosity, additives and anti-oxidants. In this second part, the remaining aspects of corrosion, such as physical and chemical properties of refractories, slag characteristics and operating conditions are discussed, linking the theory with data from industrial practice. Specifically, it was analyzed the refractory from slag-line of steel ladle.

Keywords: refractories, corrosion, steelmaking, slags.

\section{INTRODUÇÃO}

A corrosão química é normalmente a principal causa de destruição de refratários e, provavelmente, a componente mais difícil de ser controlada. Outros fatores, no entanto, também contribuem à degradação, gerando tensões no revestimento. Estas podem ser de origem térmica, tais como: gradiente térmico, dilatação, termoclase e fluência. Outras tensões são devidas a fatores mecânicos, como abrasão/ erosão, compressão, flexão, tração; seja do contato direto de metais fundidos, ou até pelo transporte de panelas, por exemplo, para o aquecimento ou o lingotamento do aço.

$\mathrm{O}$ mecanismo de ataque dos refratários em fornos industriais é um fenômeno complexo que se dá não apenas pela corrosão química, mas também pelo desgaste físico e mecânico (erosão e abrasão), mecanismos estes que atuam sinergeticamente [1].

O desenvolvimento de refratários deve propiciar maior estabilidade mecânica (estrutural) e maior resistência ao desgaste, de modo a se aumentar a produção com o mesmo revestimento. Ao mesmo tempo, prover maior economia de energia, diminuindo-se paradas para reparos e de préaquecimento [2].

$\mathrm{Na}$ primeira parte deste trabalho foram investigadas diversas características da microestrutura dos tijolos refratários, utilizados no refino de aço. Principalmente, as propriedades dos agregados, matriz, carbono, ligantes e aditivos foram analisadas [3]. Nesta segunda parte, serão abordadas as propriedades físicas dos refratários e de escórias, relacionando com a degradação dos refratários em uso. Dados de qualidade de escória utilizadas na prática industrial serão discutidos, baseando-se em análise nos diagramas de equilíbrio.

\section{PROPRIEDADES FÍSICAS DOS REFRATÁRIOS}

O tamanho e a conectividade dos poros definem a chamada porosidade aberta de um material que é resultado do sistema de ligação dos particulados sólidos. Ela possibilita a penetração e permeabilidade de escória e gases (ou vapores) no revestimento refratário. A profundidade de penetração e a natureza da corrosão definem o grau de degradação do refratário. 
O fluxo em capilares pode ser compreendido, baseandose na integração a partir da combinação das equações para fluxo laminar capilar horizontal de Poiseulle e equação geral de Laplace:

$$
l^{2}=(\mathrm{r} \cos \theta / 2)\left(\gamma_{\mathrm{LV}} / \eta_{\mathrm{L}}\right) \mathrm{t}
$$

na qual $l$ é a profundidade de penetração da escória, r o raio do capilar, $\theta$ o ângulo de contato, $\gamma$ a tensão superficial da escória, $\eta$ a viscosidade da escória e t o tempo. A inclusão de um termo de tortuosidade na equação, ajustando o termo $\mathrm{r}$, para um valor mais representativo da microestrutura foi sugerida [1].

A presença de carbono na composição dos refratários tem um efeito de redução da molhagem, aumentando o ângulo de contato [4]. A qualidade da superfície, como baixa rugosidade, também é importante para impedir a redução do ângulo de contato, como mostra a Fig. 1:

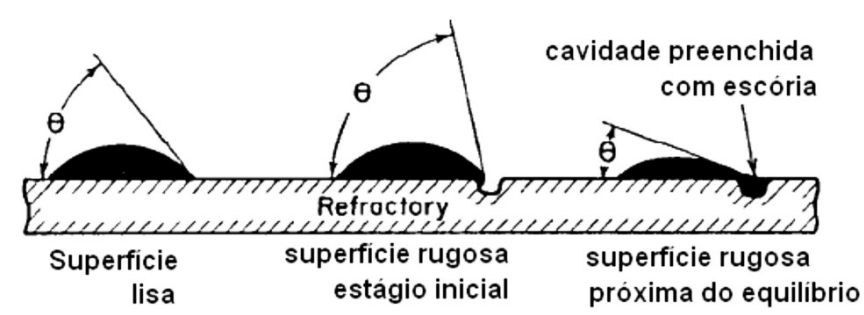

Figura 1: Efeito da rugosidade da superfície no ângulo de contato entre vidro fundido e refratário [5].

[Figure 1: Effect of surface roughness on contact angle of glass contact refractories [5]].

Refratários de panela de aço estão sujeitos a ciclos térmicos, o que requer uma elevada resistência ao choque térmico. Assim, a redução da porosidade não é aconselhável [6]. Do ponto de vista teórico, pode-se manter a porosidade total, mas diminuir-se o tamanho de poro. Na prática, a conformação de tijolos refratários é dificultada pela presença dos agregados grandes. O bloqueio dos poros pela formação de fases in situ como nitretos, carbetos e espinélio, os quais são produtos da reação entre aditivos (antioxidantes) e os gases advindos da face quente é uma importante solução para redução da permeabilidade [7]. Na microestrutura do refratário os componentes mais facilmente dissolvíveis são as partículas menores de pequeno raio de curvatura e protuberâncias de formato angular, os quais possuem maior área superficial específica. A corrosão leva ao desaparecimento de partículas pequenas e arredondamento das maiores [8].

A redução da temperatura de processo tem um efeito muito maior sobre a viscosidade da escória do que na tensão superficial e, como resultado, diminui a penetração (equação A). A redução da temperatura também reduz a difusão iônica de espécies corrosivas através da escória líquida, após a penetração. Portanto a relação temperatura/viscosidade da escória tem significativo efeito tanto na penetração da escória, como na dissolução dos refratários [1, 9-11].
Quanto mais fluida a escória, mais propensa à penetração, aumentando também a dissolução do refratário sólido na mesma, já que a reação entre as espécies químicas é mais rápida. Entretanto, se o refratário se dissolver no líquido aumentando a viscosidade, o transporte de massa através da escória será reduzido, devido ao aumento progressivo do teor do elemento (ou composto) que se dissolve na escória, passando a difusão a controlar a corrosão. Por outro lado, se a dissolução contribuir para a redução na viscosidade, a difusão passa a ser mais rápida, assim, não se forma uma camada de saturação ao redor do refratário, levando a dissolução direta, na qual a velocidade da reação passa a governar o mecanismo de corrosão, o que, em geral, aumenta a intensidade da corrosão. O controle da temperatura (de acordo com a composição da escória) passa a ser a chave à redução da corrosão, pois o aumento da temperatura, como dito, trará uma maior fluidez à escória, alterando a dissolução de indireta para direta.

\section{PROPRIEDADES DAS ESCÓRIAS E FATORES OPERACIONAIS}

As escórias são misturas de óxidos em fusão $\left(\mathrm{SiO}_{2}\right.$, $\mathrm{Al}_{2} \mathrm{O}_{3}, \mathrm{MgO}$, etc), as quais se separam do metal líquido por serem insolúveis e menos densas (sobrenadante à superfície do banho metálico). São constituídas por uma série de compostos (ex: $\mathrm{CaO}, \mathrm{CaC}_{2}, \mathrm{CaCN}_{2}, \mathrm{CaF}_{2}$ ) que servem para liberar o metal das impurezas sólidas ou dissolvidas no aço (óxidos metálicos, fósforo, enxofre). Por este motivo, cada escória é adequada a um tipo de aço e, por sua vez, o tipo de revestimento refratário deve ser adequado a ambos. Em geral, a zona dos refratários em contato com o metal apresenta corrosão mínima, enquanto as zonas do material refratário em contato com a interface metal/ escória experimentam corrosão mais forte $[4,12]$. Correntes convectivas na interface metal/escória causam em pequena escala um fluxo circulante que aumenta a dissolução [12].

A Fig. 2 mostra nitidamente o maior desgaste em linha de escória, em uma panela ao final do processo (Fig. 2a). O perfil de desgaste dos tijolos de linha de escória pode ser visto na Fig. $2 b$.

A corrosão química dos refratários é definida como o desgaste do refratário pela perda de massa e de espessura na face exposta do revestimento, como consequência do ataque químico por um fluido corrosivo (escória). No processo, a escória e o refratário tendem ao equilíbrio químico na zona de contato [13]. Portanto, a corrosão pode ser aferida, por meio da espessura residual do tijolo ao final da campanha (Fig. 2b).

$\mathrm{O}$ ataque químico do refratário pela escória líquida ocorre pela penetração via porosidade aberta e pela dissolução das fases refratárias na escória [1]. A taxa de corrosão é função de muitas variáveis, incluindo temperatura, composição da interface líquido-refratário, densidade do líquido, viscosidade, difusividade e taxa de agitação. Conseqüentemente, durante a penetração, especialmente a altas temperaturas, o líquido e o sólido reagem. 

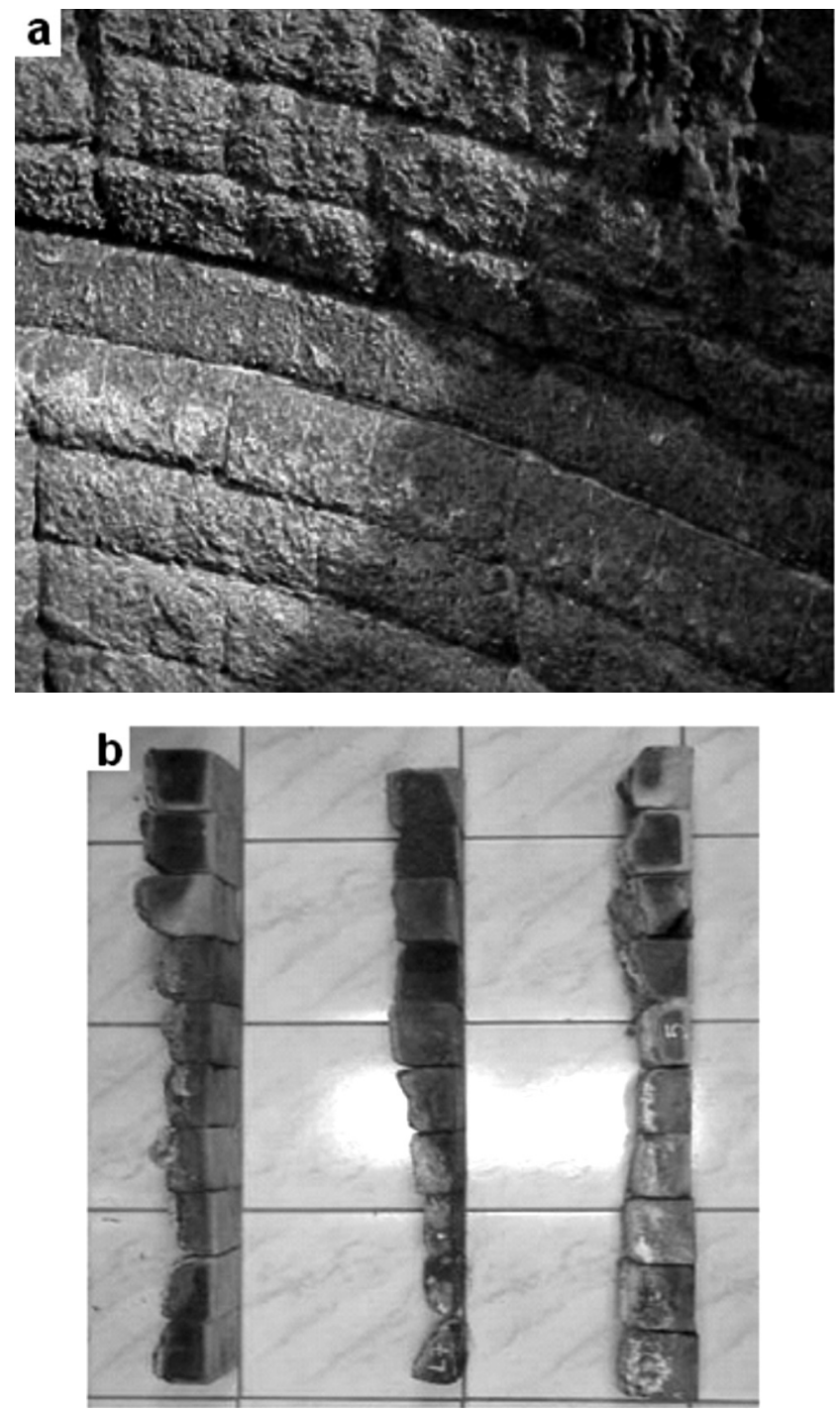

Figura 2: Detalhe do maior desgaste de linha de escória. a) Panela após uso. b) Perfil dos tijolos após uso.

[Figure 2: Detail of the increased wear of the slag line. a) Ladle after use. b) Profile of bricks after use.]

O processo de corrosão pode ocorrer pelo ataque da escória ao refratário $[9,14]$. Este ataque pode ser previsto através de diagramas de fases. Uma escória saturada em uma determinada fase sólida não ataca o refratário nessa mesma fase. Durante o refino do aço, a corrosão dos refratários é um mecanismo complexo e influenciado por muitos fatores.

Essencialmente, as reações de corrosão procedem na direção do equilíbrio químico local. Assim, devem-se utilizar escórias de composição mais próximas possível da saturação dos elementos que compõem o refratário [13]. Uma escória deve seguir o equilíbrio entre os óxidos refratários e os óxidos fluxantes (ou fundentes). O balanço entre esses irá gerar uma escória compatível com a qualidade dos revestimentos refratários empregados e que cumpra as exigências metalúrgicas. Para estas, a escória ideal é líquida, enquanto para os refratários, quanto mais sólida for a escória, menor será a corrosão. Assim, na prática utiliza-se uma escória "cremosa", ou seja, de líquidos e sólidos (Fig. 3). Os

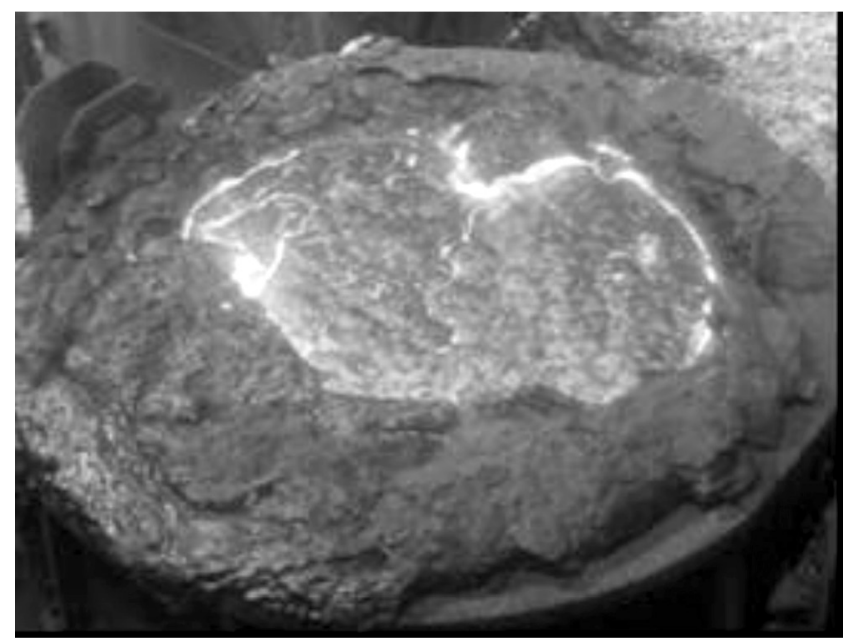

Figura 3: Escória de panela de aço.

[Figure 3: steel ladle slag.]

óxidos refratários são o $\mathrm{CaO}$ e $\mathrm{MgO}$, a adição destes alteram a temperatura liquidus e a viscosidade da escória. Os óxidos fluxantes são a $\mathrm{SiO}_{2}, \mathrm{Al}_{2} \mathrm{O}_{3}, \mathrm{FeO}, \mathrm{MnO}$ e $\mathrm{CaF}_{2}$, os quais deixam a escória mais líquida [15].

$\mathrm{O}$ diagrama ternário $\mathrm{CaO}-\mathrm{SiO}_{2}-\mathrm{MgO}$ representa os principais componentes das escórias utilizadas em refino de aço. Utiliza-se para se determinar os níveis de saturação de $\mathrm{CaO}$ e $\mathrm{MgO}$ das escórias com os revestimentos de magnésiacarbono e doloma-carbono. Para uma melhor compreensão e interpretação das escórias é comum considerar o corte isotérmico na temperatura de $1600{ }^{\circ} \mathrm{C}$. A Fig. 4 mostra os pontos de saturação da escória em $\mathrm{MgO}, \mathrm{CaO}$ e de dupla saturação em $\mathrm{MgO}$ e $\mathrm{CaO}$.

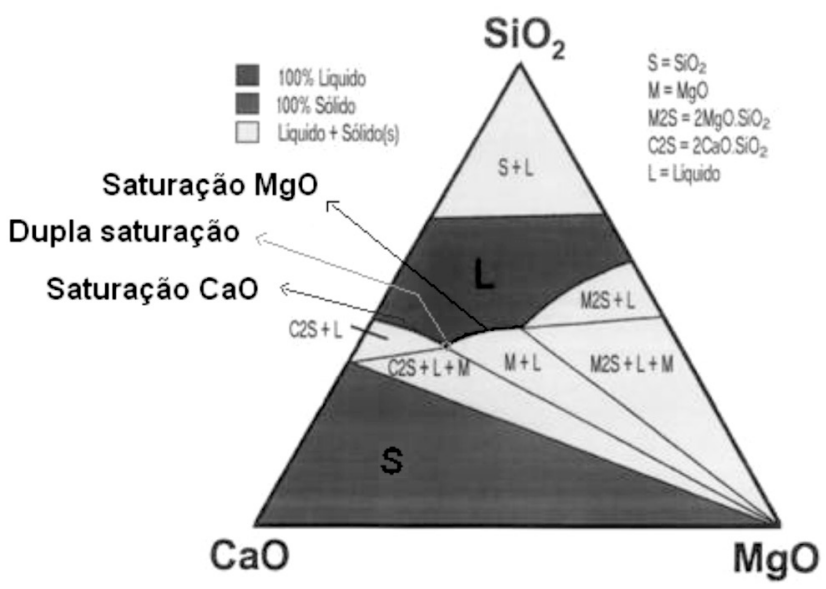

Figura 4: Linhas de Saturação $\mathrm{CaO}, \mathrm{MgO}$ e Dupla Saturação no sistema $\mathrm{CaO}-\mathrm{MgO}-\mathrm{SiO}_{2} \mathrm{~T}=1600{ }^{\circ} \mathrm{C}[16]$.

[Figure 4: Saturation Lines $\mathrm{CaO}, \mathrm{MgO}$ and Dual Saturation in the system $\mathrm{CaO}-\mathrm{MgO}-\mathrm{SiO} 2 \mathrm{~T}=1600^{\circ} \mathrm{C}$ [16].]

Na prática industrial, não basta apenas o projeto de uma escória saturada nos elementos do material refratário, pois a escória pode variar de composição e não ter uma composição heterogênea, por uma série de fatores. Principalmente, as 

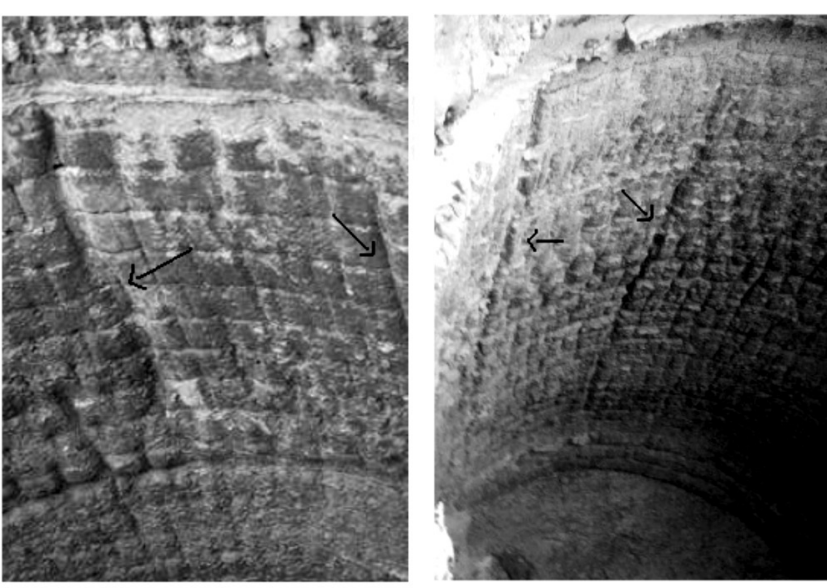

Figura 5: Desgaste excessivo devido à presença de fluorita em condição de mistura insuficiente.

[Figure 5: Excessive wear due to the presence of fluorite in conditions of insufficient mixing.]

adições de elementos de liga, a fim de se acertar a composição do aço, podem alterar a composição da escória, deixando-a, por exemplo, mais ácida devido à formação de sílica (advinda da adição de FeSi). Durante a produção, o tempo hábil para se ajustar a composição da escória nem sempre é suficiente, mesmo para aciarias que fazem análise on-line de escória. Além disso, a composição local da escória pode variar por cristalizações, falta de mistura, respingos, etc, perdendo-se a saturação. Salienta-se também a presença de outros óxidos fundentes, cujos teores podem variar bastante, gerando compostos eutéticos (líquidos).

O emprego de fundentes enérgicos como a fluorita $\left(\mathrm{CaF}_{2}\right)$, utilizada muitas vezes para se obter uma ação rápida para se liquefazer uma escória e aumentar a solubilidade do $\mathrm{CaO}$ na escória (necessária, por exemplo, à dessulfuração do aço), é bastante prejudicial aos refratários. O desgaste do revestimento refratário é severo mesmo que isto ocorra em uma única corrida, já que a diminuição da temperatura solidus da escória leva a intensa penetração na matriz refratária (Fig. 5). É claro que uma escória muito líquida, não saturada nos constituintes do refratário, sempre vai impingir um desgaste excessivo ao revestimento, com ou sem a presença de fluorita [15]. Destaca-se ainda a presença de $\mathrm{FeO}$, cujo efeito de formação de líquidos é ilustrado na Fig. 6.

$\mathrm{O}$ ataque químico em refratários doloma e $\mathrm{MgO}-$ $\mathrm{CaO}-\mathrm{C}$ sinterizados foi investigado [17]. Nesse estudo, foi constatado que o desgaste dos refratários é reduzido com o aumento da concentração de $\mathrm{CaO}$ em tijolos frente a escórias com baixo teor de ferro e baixa razão $\mathrm{CaO} / \mathrm{SiO}_{2}$. Porém, o desgaste aumenta em escórias de alta basicidade e elevados teores de óxido de ferro. A razão para esse comportamento é a fácil formação compostos entre os óxidos de ferro e cálcio $(\mathrm{CaO} .2 \mathrm{FeO})$, com baixa temperatura de fusão.

A corrosão de refratário $\mathrm{MgO}$ se dá pela formação de uma camada de magnesiowustita, $(\mathrm{Mg}, \mathrm{Fe}) \mathrm{O}$, devido a rápida difusão do $\mathrm{Fe}$, comparado a outras espécies [18]. A camada de magnesiowustita também é atacada, e o equilíbrio
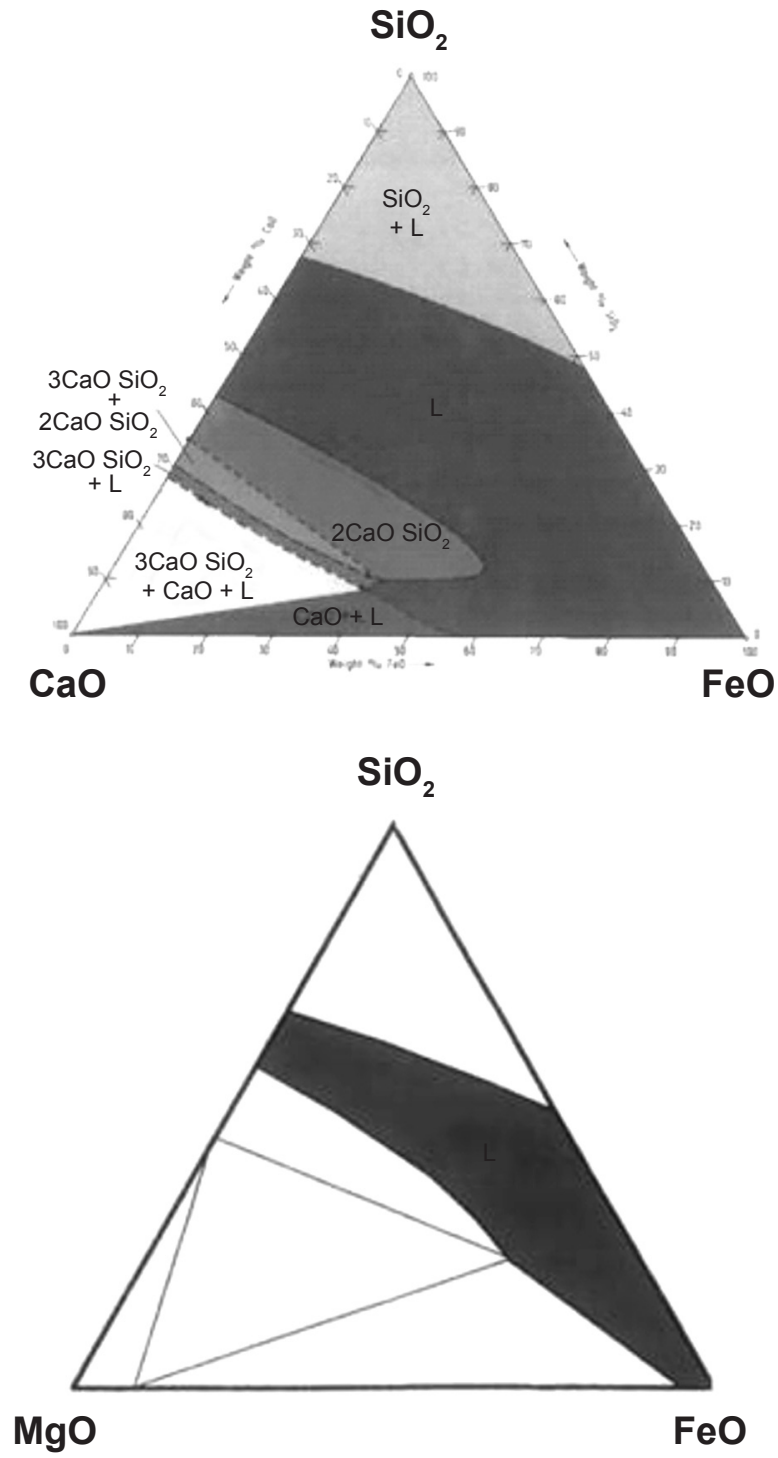

Figura 6: Diagramas Ternários $\mathrm{CaO}-\mathrm{SiO}_{2}-\mathrm{FeO}$ e $\mathrm{MgO}-\mathrm{SiO} 2-\mathrm{FeO}$. $\mathrm{T}=1600{ }^{\circ} \mathrm{C}[16]$.

[Figure 6: Ternary Diagram $\mathrm{CaO}-\mathrm{SiO} 2-\mathrm{FeO}$ and $\mathrm{MgO}-\mathrm{FeO}-\mathrm{SiO} 2$. $\left.T=1600^{\circ} \mathrm{C}[16].\right]$

entre dissolução (interface com a escória) e crescimento (interface com o refratário) é controlado pela temperatura e composição da escória.

A oxidação do carbono devido ao óxido de ferro da escória (e/ou do oxigênio da atmosfera do forno) é responsável pela formação de uma camada descarbonizada, facilitando à penetração $[1,19]$. O óxido de ferro leva à perda de carbono do grão de magnésia, diminuindo a resistência à corrosão do mesmo [20].

De um modo geral, a presença de $\mathrm{FeO}$ diminui o ponto de fusão e a viscosidade da escória, acarretando numa maior agressividade da mesma sobre os refratários, diminuindo consideravelmente a vida útil dos revestimentos [13]. Como dito anteriormente, a redução da viscosidade aumenta a penetração da escória e a dissolução dos refratários na mesma. 
A dissolução do refratário pode ser controlada pela taxa de reação na interface escória-refratário ou pela taxa de transporte difusivo das espécies reagentes à interface através da escória. Se o produto da reação sair livremente da zona de reação, neste caso, tem-se uma corrosão ativa (ou direta) e normalmente bastante severa. $\mathrm{O}$ ataque também pode ser controlado pelo transporte difusivo através da escória ou através de uma nova fase sólida, a qual se forma na interface original escória-refratário. Se a difusão é mais lenta que a reação química, a camada sólida cresce na interface e a difusão dos reagentes ou dos produtos através dessa camada governa a corrosão. Se esta camada ficar aderida ao refratário, ter-se-á o mecanismo indireto de corrosão, podendo levar a uma condição de passivação, ou seja, a corrosão é mais lenta, aumentando-se a vida útil do revestimento [1, 21, 22]. Um bom exemplo de camada protetora à corrosão é a formação da camada de silicato dicálcico $\left(2 \mathrm{CaO} . \mathrm{SiO}_{2}\right)$ no contato com escórias de sílica em refratários doloma-C, ilustrado na Fig. 7.

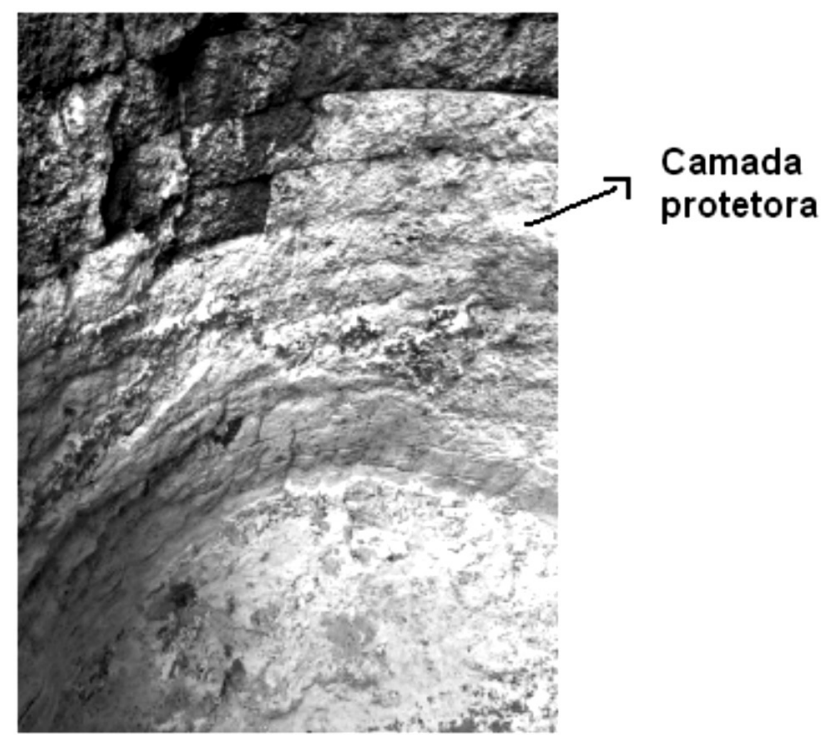

Figura 7: Camada protetora de silicato dicálcico. Contato com escórias em refratários doloma-C.

[Figure 7: Protective Layer dicalcium silicate. Contact slag with Doloma-C refractories.]

Embora o efeito deletério da presença de óxido de ferro nas escórias seja conhecido, como explicado anteriormente, seu controle não é fácil no dia-a-dia de uma aciaria. A Fig. 8 mostra uma ampla variação dos teores de óxido de ferro nas escórias. Primeiramente, é mostrada a variação no forno elétrico a arco (FEA). Como parte da escória do FEA passa à panela, torna-se um fator de variação da composição da escória nesta última. Depois, tem-se a variação da composição da escória, logo após o aço ser vazado, recebendo os primeiros ajustes de sua composição, com a introdução de certos materiais (desoxidantes, calcários, etc). Por fim, temse a variação no tratamento que ocorre no forno panela, onde ocorrem os ajustes finais da composição do aço e escória. Assim, observa-se uma grande amplitude na variação do teor de $\mathrm{FeO}$, intrínseca ao processo metalúrgico. De modo similar à variação do $\mathrm{FeO}$, mas não tão acentuadamente, outros compostos também variam seus teores na escória ao longo processo, como $\mathrm{MnO}, \mathrm{CaO}, \mathrm{SiO}_{2}$, etc. Destaca-se que na saída do forno panela o teor de FeO é suficientemente baixo, como é desejado tanto para os refratários, quanto para a qualidade do aço.

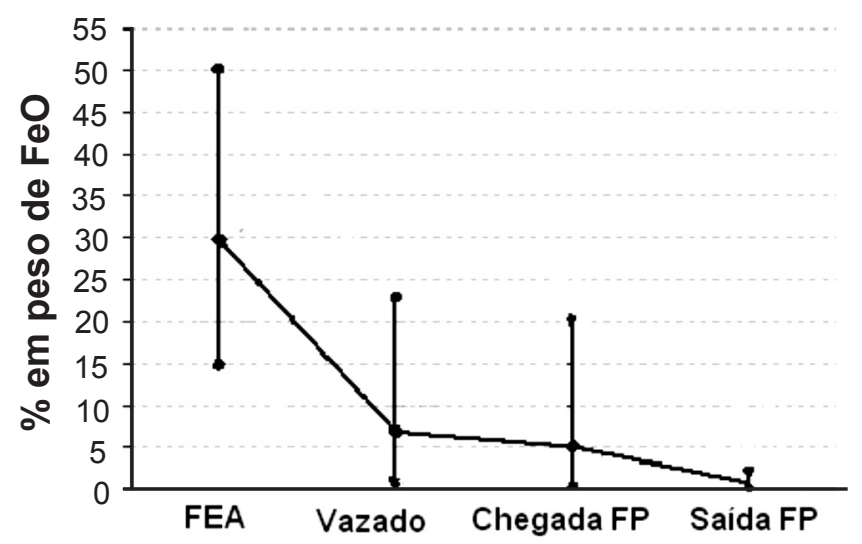

Figura 8: Valores médios do teor de $\mathrm{FeO}$ (\% em peso) nas etapas do processo (FEA: forno elétrico a arco; FP: forno panela). Valores máximos e mínimos são dados experimentais.

[Figure 8: Mean values of $\mathrm{FeO}$ content (wt\%) in the steps of the process (EAF: electric arc furnace; FP: ladle furnace). Maximum and minimum values are experimental data.]

A corrosão do material em contato com a escória é um mecanismo de desgaste em três estágios. O primeiro é a oxidação do carbono amorfo ou do grafite, formando uma camada descarbonizada, portanto de maior molhagem. Isto favorece a penetração ou infiltração da escória na porosidade do refratário, iniciando o processo de dissolução ou difusão (segunda etapa), processo químico em que o material refratário é dissolvido na escória líquida. A penetração da escória no refratário causa efeitos químicos e termomecânicos. O terceiro estágio é a erosão, retirando os agregados e expondo novamente o material refratário ao ataque pelos gases e ao movimento da escória [1, 4, 14]. A Fig. 9 mostra esses passos de forma esquemática.
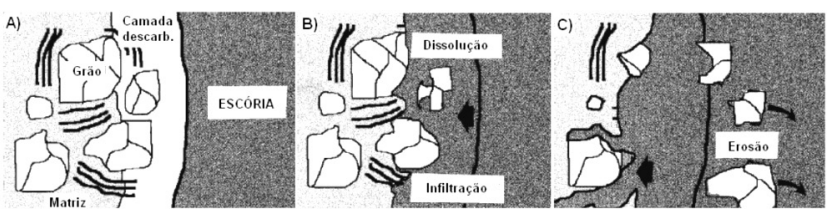

Figura 9: Esquema geral do mecanismo de corrosão de refratários óxido-carbono [1].

[Figure 9: Schematic of the general mechanism of corrosion of oxide-carbon refractories [1].]

Os diagramas de equilíbrio apontam para a composição ideal de uma escória. Mas, face ao discutido anteriormente (Fig. 8), esta condição nem sempre é obtida e mesmo mantida durante o processo industrial de refino do aço. Portanto, a 
qualidade de um refratário passa a ser um diferencial, em termos de maior vida útil de um revestimento. Esta qualidade está relacionada com os parâmetros de microestrutura, discutidos na primeira parte deste trabalho [3].

Conforme o mecanismo proposto (Fig. 9 [1]), a qualidade do refratário é primordial. Por exemplo, a qualidade dos grãos/agregados, em termos de pureza e menor área superficial, é diretamente responsável por uma maior resistência à dissolução. Similarmente, o carbono é um fator chave para se aumentar a resistência à corrosão. Uma solução, portanto, seria o aumento do teor desse componente no refratário. No entanto, a perda de carbono significa que o refratário ficará mais poroso, com uma maior superfície exposta ao contato com a escória. Assim, a qualidade do carbono, com maior resistência à oxidação, e através de mecanismos que bloqueiam os poros, com a adição de antioxidantes, são fundamentais. Considera-se igualmente importante a homogeneidade de distribuição de carbono e antioxidantes na microestrutura do refratário.

$\mathrm{Na}$ terceira parte dessa série de artigos será investigada a qualidade de refratários de diferentes fabricantes de refratários.

\section{CONCLUSÃO}

Por mais que seja controlado um processo, a resistência à corrosão depende em muito da qualidade do revestimento refratário. Na prática industrial é difícil se manter uma condição permanente de saturação da escória com os elementos do refratário. Além disso, a penetração da escória no refratário, por exemplo, em conseqüência da descarbonização da superfície do mesmo, pode levar a uma composição local diferente da de equilíbrio, iniciando o processo de corrosão. Esta prossegue por sua vez, por um mecanismo de dissolução da matriz e erosão dos agregados.

\section{AGRADECIMENTOS}

O autor agradece ao Eng. Luciano Ramos Marques da Gerdau Riograndense S.A. e ao Eng. MSc. João Paulo Ferreira da Magnesita S.A..

\section{REFERÊNCIAS}

[1] W. E. Lee, S. Zhang, V II Int. Conf. Molten Slags, Fluxes and Salts, The South African Institute of Mining and Metallurgy (2004) 309-319.

[2] T. P. Fredman, Scandinavian J. Metallurgy 29 (2000) 232-258.
[3] S. R. Bragança, Corrosão de refratários utilizados na siderurgia. Parte I: Propriedades Microestruturais, Cerâmica 58, 347 (2012).

[4] A. M. Segadães, Refractários, Universidade de Aveiro (1997).

[5] J. E. Comeforo, R. K. Hursh, Wetting of $\mathrm{Al}_{2} \mathrm{O}_{3}-\mathrm{SiO}_{2}$ Refractories by Molten Glass: I, Measurement of Wetting, J. Am. Ceram. Soc. 35, 5 (1952) 130-34.

[6] V. C. Pandofelli, M. T. Fadel, Cerâmica 35, 228 (1989) $1-6$.

[7] W. E. Lee, R. E. Moore, J. Am. Ceram. Soc. 81, 6 (1998) 1385-1410.

[8] W. E. Lee, S. Zhang, Int. Mater. Rev. 44, 3 (1999) 77104.

[9] S. Jansson, V. Brabie, P. Jonsson, Scandinavian J. Metallurgy 34 (2005) 283-292.

[10] M. Guo, S. Parada, P. T. Jones, J. Van Dyck, E. Boydens, D. Durinck, B. Blanpain, P. Wollants, Ceram. Int. 33 (2007) 1007-1018.

[11] M. A. Van Ende, M. Guo, P. T. Jones, B. Blanpain, P. Wollants, Ceram. Int. 35 (2009) 2203-2212.

[12] A. Lucio, Físico-química metalúrgica, Parte 2, UFMG, MG (1981).

[13] D. A. Brosnan, Corrosion of refractories, Refractories Handbook, Ed. C. A Schatcht, Marcel Dekker Inc., New York, EUA (2004).

[14] S. Jansson, V. Brabie, P. Jonsson, Scandinavian J. Metallurgy 5, 2 (2008) 99-107.

[15] E. B. Pretorius, R. C. Carlisle, Slags and the Relationship with Refractory Life and Steel Production, LWB Refractories (1996) 53-57.

[16] Committee for fundamental metallurgy, Slag Atlas, Verlag Stahleisen, Dusseldorf, Alemanha (1981).

[17] H. Toritani, T. Kawakami, H. Takahashi, I. Tsuchiya, Taikabutsu (Refractories) 36 (1984) 29-33.

[18] E. T. Turkdogan, Physicochemical properties of molten slags property control by processing, The Metals Soc., London, Inglaterra (1983)..

[19] R. A. Mattila, J. P. Vatanen, J. J. Harkki, Scandinavian J. Metallurgy 31 (2002) 241-245.

[20] R. A. Landy, Magnesia Refractories, Refractories Handbook, Ed. C. A. Schatcht, Marcel Dekker INC., New York, EUA (2004).

[21] S. Kienow, Refractory materials, Ceramics Monographs - A handbook of ceramics, Verlag Schmid GmbH Freiburgi. Brg., Alemanha (1979).

[22] W. E. Lee, D. D. Jayaseelan, S. Zhang, J. Eur. Ceram. Soc. 28 (2008) 1517-1525.

(Rec. 15/09/2011, Rev. 16/02/2012, Ac. 19/04/2012) 